\title{
Does PSM matter among innovative government managers?
}

\author{
Ellysson Fernandes Rosa
}

Government of Goiás, Goiânia, Brazil, and

Estela Najberg and Marcos de Moraes Sousa

FACE, Federal University of Goiás, Goiânia, Brazil

Abstract

Purpose - The need to improve the efficiency and quality of public services has increased the interest in innovation. This study seeks to understand the relationship between the Public Service Motivation (PSM) index and the profile of strategic-level public servants who are considered innovative.

Design/methodolog/approach - Questionnaires were applied to the group of government managers who registered their projects in an innovation competition. Data were analyzed using $t$-test, multiple correspondence analysis (MCA) and hierarchical cluster analysis (HCA).

Findings - This paper concluded that the PSM level of these innovative public servants is significantly greater than public servants overall. In terms of the profile of these innovative government managers, it was found that the majority were female, with a high level of education and a background in Information Technology.

Practical implications - The discovery that innovative government managers have a significantly higher $\operatorname{PSM}(\phi<0.05)$ than public servants overall may be relevant, because it confirms a statistical tendency that it would be advantageous for policy-makers to invest in actions that increase public servant PSM since these servants with high PSM are more innovative.

Originality/value - This article has sought to fill a gap in studies that associate the level of PSM with the innovation practices in the public sector, as well as verify the profile of public servants with high levels of motivation in public service (PSM).

Keywords Innovation, PSM, Public service motivation, Public service, Public management,

Government managers

Paper type Research paper

\section{Introduction}

Social demands create pressure on public agents to solve problems that affect the lives of citizens, and it is through innovation that viable responses to the challenges that public administration faces emerge, especially in an environment faced with a lack of resources. This is why the need to improve the efficiency and quality of public services has increased the interest in innovation (Arundel \& Huber, 2013). The mentioned authors also point out that the public sector represents 20 to $30 \%$ of the GDP of developed economies, which could indicate why it is not surprising that there is a growing interest in encouraging innovation in public services.

(C) Ellysson Fernandes Rosa, Estela Najberg and Marcos de Moraes Sousa. Published in Revista de Gestão. Published by Emerald Publishing Limited. This article is published under the Creative Commons Attribution (CC BY 4.0) license. Anyone may reproduce, distribute, translate and create derivative works of this article (for both commercial and non-commercial purposes), subject to full attribution to the original publication and authors. The full terms of this license may be seen at http:// creativecommons.org/licences/by/4.0/legalcode

The authors thank Professor Dr. Flávia Neri Meira de Oliveira for the methodological contribution to this work.

Funding: This research received no specific grant from any funding agency in the public, commercial or not-for-profit sectors.

Declaration of conflicting interests: The author(s) declare(s) that there is no conflict of interest.

Accepted 12 February 2020 
REGE 27,3

\section{4}

We know that innovative projects do not exist without the participation of people who are interested in creating and executing them, but the characteristics of public administration make it more difficult to motivate public servants to innovate. Borins (2001), for example, states that the public sector has the following disadvantages: the registration of patents does not reward inventors because they are the property of the state, and there is a rejection of careers in the public sector by innovative people (adverse selection). In addition to the problems already mentioned, a lack of market competition, bureaucratic rigidity and a lack of autonomy (Gallouj \& Zanfei, 2013) are factors that make it difficult to be innovative in this sector.

Given the barriers mentioned by these authors, it is clear that ways need to be found to motivate public servants to promote innovation. In relation to the motivation to act, the Public Service Motivation (PSM) construct, validated by James L. Perry (Perry, 1996), has been studied over the last two decades within the context of public administration. This construct deals with public motivation from the perspective of seeking the common good through intrinsic values. This model has gained importance because, among other factors, it is focused on the reality of motivation within the context of public service. A growing number of empirical studies about PSM suggest the value of the PSM construct in the study of motivation within the public sector (Ballart \& Riba, 2015; Jacob, Schiffino, \& Biard, 2016; Leisink \& Steijn, 2009; Liu, 2009; Perry, 1997; Vandenabeele, 2009).

Considering the importance of motivation in the context of public administration, this study has attempted to answer the following questions: Is there a difference in the level of PSM among public servants in general as compared to innovative public servants? What is the PSM profile of these innovative public servants?

The objective of this article is to verify if notably innovative public servants have a substantially higher PSM than public servants in general, and also to establish the relationship between the PSM index and the social-demographic profile of public servants who are considered innovative due to their participation in a public sector innovation competition.

\section{Public service motivation (PSM)}

Public service can be defined as any service performed for the public, by public servants hired by the state, with administrative functions and with a responsibility for the public good; along these lines, the PSM can be considered as part of the ethos of public service itself which consists of contributing to the well-being of society (Horton, 2008).

In the Brazilian public service, after the period of the old republic, patrimonialism and patronage have been the target of public managers culminating in the implementation of bureaucratic public administration (Costin, 2010). But overcoming these problems is not enough to achieve an efficient public service, one of the reasons why new public management reform has emerged in Brazil (Bresser-Pereira, 2009). The public service performance, however, is influenced by social control (Struecker \& Hoffmann, 2017) and the motivation of the public servant, who is a fundamental agent in this process of change (Schott, van Kleef, \& Steen, 2015).

In contrast to theories focused on human needs, such as those of Maslow (1943) and Herzberg (1987), the labor psychologist and scientist Albert Bandura elaborated the social cognitive theory. This theory argues that human behavior can be modified by reinforcing events that influence the way employees think (Bandura, 1977). Social cognitive theory has had a significant impact on the literature regarding work motivation, because values, and not human needs, play the dominant role in an individual's motivation. This transition from needs to values is a key factor for studies of motivation related to public service (Bandura, 1969; Latham, 2007; Perry \& Hondeghem, 2008). Authors who study the public sector, such as Norberto Bobbio, recognize that it is the cultural rather than the economic subsystem that is the most important, based on the internalization of social values and an adherence to norms (Bobbio, 2000).

The idea that motivation in public service is characterized and based on values was fundamental to the creation of the PSM construct. In part, this construct was a response to the 
public choice theory which defends the perception that public servants are motivated by selfinterest (Prebble, 2014). Another theory that supports the assumption that man is individualist, opportunistic and materialist is the agency theory. In contrast, the stewardship management theory arose, and it argues that agents, even when they have interests that diverge from the interests of the principal, behave in a cooperative manner because they consider this to be a more rational attitude (Davis, Schoorman, \& Donaldson, 1997).

Perry (1996) has transformed the concept of motivation in public service when he proposed four dimensions within the PSM construct, specifically, compassion, self-sacrifice, attraction to public policy-making and commitment to the public interest. He also validated his scale with 24 items based on a confirmatory factor analysis. Various authors have recognized the value of the PSM construct in public administration as well as Perry's scale (Koehler \& Rainey, 2008; Pandey \& Stazyk, 2008).

One relevant study that contributed to the solidification of the PSM construct was performed by Vandenabeele and Walle (2008). They used data from the 2004 International Social Survey Program (ISSP) and an international group of professionals to investigate PSM in 38 different countries with a total of 52,550 respondents (Vandenabeele \& Walle, 2008). This research made it possible to observe and validate the PSM level of public servants in these countries; the relationship between PSM and innovation, however, has not been studied in further depth.

Even though various authors defend the PSM construct (Bellé, 2013; Buiatti \& Shinyashiki, 2011; Crewson, 1997; Perry, 2010), Davis (2010) criticizes the fact that these authors accept that public servants are both selfish and altruistic, but do not explain empirically under which circumstances they display these different behaviors. Jacobson (2011) has found that most public servants in two American government organizations sought their jobs for pragmatic rather than altruistic reasons.

However, PSM studies are not naive in terms of human nature and consider that organizations need to use intrinsic as well as extrinsic incentives to motivate employees, since people are both selfish and altruistic (Perry \& Hondeghem, 2008).

Most of the knowledge of public sector motivation has come from theories tested in the private sector (Perry \& Hondeghem, 2008). Despite criticism, PSM is the most mature construct dealing with public service motivation, as it has received considerable attention over the past two decades and interest in it continues to grow (Liu \& Perry, 2016).

Currently, the effectiveness of PSM has been investigated, considering the different contexts it is inserted. The impact of the organization's institutional logic, for example, affects PSM, because people with high PSM in organizations that do not allow contributing to society in any way, generate low job satisfaction and burnout (Van Loon, Vandenabeele, \& Leisink, 2015). In addition, analysis of PSM's relationship to leadership aspects such as subordinate pro activity and servant leadership style has shown a positive correlation with PSM (Liu, Perry, Tan, \& Zhou, 2018). Another current concern of PSM scholars is the individual perception of the concept of PSM that can affect the results of empirical research. It happens because understanding individual perceptions of what is being motivated for the public interest can improve the concept of PSM (Schott et al., 2015).

Motivation by itself does not guarantee the providing of good public service. Public service has increasingly become the target of criticism due to its apathy and poor performance (Brehm \& Gates, 1999). The energy generated by this motivation needs to promote the necessary results in public administration, mainly through radical or incremental innovation.

\section{Innovation in public service}

The concept of innovation is very broad and has been analyzed by a variety of authors from different perspectives. Innovation does not necessarily mean radical change. On the contrary, 
REGE 27,3

\section{6}

most of the time it occurs in an incremental fashion (Tidd, Bessant, \& Pavitt, 2008). To distinguish an innovation from a simple change, Jacobi and Pinho (2006) point out two fundamental ideas that are used to evaluate projects in the "Public Management and Good Citizenship" competition; first, the project should involve substantial change; secondly, these changes should be repeatable.

It is challenging to deal with innovation strictly within public service, since this concept is still in its development stage (Gallouj \& Zanfei, 2013). Although the concept of innovation is developing, 30 years ago the focus of innovation was almost exclusively centered on the use of new information technologies, which corresponds to the innovation assimilation perspective (Djellal, Gallouj, \& Miles, 2013).

In contrast to the assimilation perspective, we have the following innovation approaches: the demarcation, which deals with differentiating a company from its competitors through changes in product and service characteristics; the inversion approach, which can be seen as a perspective that is exclusively focused on services in response to the dominant industrial perspective; and the integration approach, which takes the opposite approach from the inversion method by integrating products and services (Djellal et al., 2013).

Along with these four theoretical perspectives Gallouj and Zanfei (2013) also refers to other types of innovation: (1) strategic innovation (new objectives, purposes or values); (2) position innovation, involving new contexts, customers or partners; (3) governance innovation, such as new democratic institutions and new forms of participation; and (4) rhetorical innovation, when new forms of language, concepts and definitions are applied (Hartley, 2005).

Innovation in Brazil has been happening both nationally and locally (Sousa, Ferreira, Najberg, \& Medeiros, 2015b). Moreover, in Goiás, the actions have taken place in both the private and public sectors. In the private sector, the SEBRAE's Program - Local Innovation Agents (ALI) has served 35 food companies in the west of Goiás, encouraging innovation (PAULLA, 2015). In the public sector, the State Department of Health achieved first place in the HUBGOV innovation award, with the creation of the "Fiquei Grávida" cellphone application that will allow pregnant women from all over the state to access tips and schedule prenatal appointments (Goiás, 2018). Moreover, there is a trend in the public sector to create labs and innovation teams (Cavalcante, Magalhães, \& Goellner, 2019).

To better adapt innovation analysis to public service, Bloch and Bugge (2013) developed a model to measure innovation in public administration by the Measuring Public Sector Innovation in the Nordic Countries (MEPIN) project in Scandinavia. This model has proved useful in understanding innovation in public service as well as measuring it. In addition, Schein (1990) argues that the force of a culture is determined, among other factors, by the stability of the group, its longevity and the intensity of its learning experiences - an idea which is consistent with group work rather than individual projects. In this sense, one of the challenges of innovating in public administration is stepping outside the sphere of individual actions and making the program continuous, collective and large scale. The challenge that public administration faces is to motivate their public servants to be innovative, not just occasionally but on a daily basis (Borins, 2001).

This leads us to one of the reasons for this research, because innovation in the public sector remains an unexplored "black box"; there are gaps in this area on the theoretical as well as the empirical and methodological levels (Gallouj \& Zanfei, 2013).

\section{Innovation and PSM in public service}

What is a public sector innovation? Schumpeter understands innovation as a gradual process that improves the economy through changes in products, processes and markets (Schumpeter, 2008). Projects that are considered innovative in the public sector are related to improving the efficiency and user satisfaction of the public service (Sousa et al., 2015b). 
There are many articles that associate PSM with performance (Bellé, 2013; Mann, 2006; Stazyk, 2013; Taylor \& Taylor, 2011), but we have found none that relates PSM and innovation. In addition to this, innovation in the public sector possesses its own nuances, given that competition between companies - an essential element of motivation in the private sector - is not present in the public sector (Djellal et al., 2013). In this context, the concern with the principles of public service (equality, justice and continuity) turns into a source of motivation within the public sphere. The use of this logic makes the verification of the influence of PSM on innovation interesting, given that the PSM is made up of dimensions that touch on the principles of public service.

An example of this type of consideration can be found in the research of Kernaghan (2011), in which the performance of public service employees is seen as being the result of their engagement, which, in turn, is intimately associated to motivation. The author also emphasizes the fact that there are studies indicating a positive correlation between PSM and individual performance. On the other hand, Bozeman and Su (2014) warn that PSM has been contaminated by an "inspirational bias" that has made many scholars theorize based on their own values and aspirations.

Crewson (1997) in turn infers that public servants are more motivated by intrinsic factors than their counterparts in the private sector. These studies show that value-based motivation influences individual behavior in terms of the organization; these discoveries show the importance of stimulating PSM. Crewson (1997), however, admits that it is quite difficult to measure the connection between PSM and individual performance, mainly because of lack of information and data that would permit such an analysis.

In terms of the social-demographic profile, Bright (2005) identifies some personal characteristics of public servants with high levels of PSM. Most of these public servants are women on a managerial level with high levels of education.

In Brazil, where this research was conducted, we were able to find just one study on PSM in the databases that we accessed: CAPES, SCIELO and Google Scholar. This was the research conducted by Buiatti \& Shinyashiki (2007) and published in (2011). In this article, the authors translated and validated Perry's original PSM scale (1996), and concluded that the scale is appropriate for the study sample and that it can be considered an explanatory study for further research. To reach their conclusions, they gave a questionnaire to 190 public servants in the city of Ribeirão Preto, São Paulo state. The profile of this sample was not restricted to a single government body or a single type of career, and thus it reflects public servants in a general sample.

Although research on motivation to innovate is incipient in Brazil, public sector awards have demonstrated the degree to which innovation is valued there. Two main examples are the Federal Public Administration Innovation Competition, held annually by the National School of Public Administration - ENAP, and the Innovare Award, which seeks to identify practices that contribute to the improvement of justice in Brazil.

For Sousa et al. (2015b), from an organizational perspective, the big challenge is to motivate the servers and channel this motivation to innovation. Thus, the elements that underpin the operationalization of this research are the verification if innovative public servants have a substantially higher PSM than public servants in general, and also the relationship between PSM index and the profile of these innovative public servants.

\section{Methodology}

The government managers that are considered innovative, who are the subjects of this study, are part of the strategic-level career, which was created by law and went into operation in the state of Goiás in Brazil in 2002.

After the program completed ten years of operations in 2012, this category's union (SINDGESTOR) held a project competition and handed out awards to the three most 
REGE 27,3

\section{8}

innovative projects that have made relevant contributions to public administration in the state. It should be emphasized that the existence of an environment which is favorable or unfavorable to innovation can vary from administration to administration; this is why the union directors' decision to evaluate "the first ten years" was quite appropriate in order not to restrict the study to a single administration.

Although the period after the public management reform (1995) is marked by an effervescence of innovation in the public sector (Sousa et al., 2015b), the main reason for choosing this time range (2002-2012) was to use the database raised by the union through the project competition with a history of projects of the initial ten years of this career.

The projects were evaluated based on their relevance to improving management, their social impact and also to the following economic criteria: the amount of money saved by the state, the monetary value of increased revenues and the monetary value of financial resources and investments attracted to the state. It is worth noting that of the 61 innovative projects, only 29 had a social positive impact with no measurable economic return.

Out of a total of 730 government managers, 124 participated in the project competition. We know that government managers who did not participate in the competition may have made relevant contributions also, but participation in a competition officially held by the union was the best criteria in this context to identify government managers who have stood out as innovative. It should be noted that it is common practice to evaluate innovation by examining project competitions (Borins, 2000; Brandão \& Bruno-Faria, 2013; Ferreira, Najberg, Ferreira, Barbosa, \& Borges, 2014; Jacobi \& Pinho, 2006; Sousa, Ferreira, Najberg, \& Medeiros, 2015a; Williams, 2012).

The following hypotheses were created to achieve our first specific objective, namely, to identify the PSM levels of innovative government managers and compare them with the PSM levels for general public servants found in the research developed by Buiatti \& Shinyashiki (2011):

H1. The average PSM of innovative government managers is greater than the average of public servants in general.

In order to test this hypothesis, we used the student $t$-test, which is sufficient when there are only two conditions (Dancey \& Reidy, 2013), which, in this case, were the overall PSM and the PSM of innovative government managers. However, it should be emphasized that we have not sought to determine causality but rather a statistical likelihood.

We used multiple correspondence analysis (MCA) and hierarchical cluster analysis (HCA), also known as grouping analysis, to achieve our second specific objective, namely, analyzing the PSM profile in terms of the following characteristics: gender, marital status, educational specialty, age, level of education, type of public servant, length of public service and current position.

To analyze the dependence between variables, the regression method would be superior, because the dependent variable is to be studied as a function of, or in relationship to, any factors of interest (the independent variables) and also an appropriate test for continuous data (Cohen, Cohen, West, \& Aiken, 2013). However, we choose to analyze interdependence for the second objective because to analyze interdependence of categorical variables, grouping analyses would be more appropriate (Hair, Anderson, Tatham, \& Black, 2005; Harman, 1976; Mori, Kuroda, \& Makino, 2016), since our goal was to know the profile of these innovative public servants whose PSM is higher.

For this study, the use of MCA was important because it enables the association of government manager type with demographic characteristics, grouped by PSM levels of low, medium and high. The HCA was used to analyze the sample similarities based on the distribution of the variables. The MCA and HCA are the most appropriate multivariate 
analysis techniques for grouping analysis given that the objective is to evaluate associations among the variables (Hair, Anderson, Tatham, Black, \& Trans. 5, 2005).

The data were collected through a PSM scale questionnaire which was given to public servants in the state of Goiás, who participated in the first innovative project competition sponsored by SINDGESTOR. The PSM scale consisting of four dimensions and 24 5-Likert questions used in this study was previously validated in Brazil by Buiatti and Shinyashiki (2011), and were the same questions that were used by the original Perry scale (1996).

So, this research can be classified by the following aspects: (1) quantitative approach with hypothesis tests, (2) as to the objectives, it is an explanatory survey; (3) as to the data collection method, we used document analysis of the innovation competition and a questionnaire and (4) about the type of data, we used secondary, with analysis of the SINDGESTOR innovative project competition and primary, with a collection of data by the questionnaire.

In order to maintain a $95 \%$ level of confidence and a sample error of $5 \%$, the study needed a total of 94 error-free responses within this population of 124 public servants who participated in this first innovative government project competition. However, a goal of 100 public servants was stipulated, given that the quality of multivariate analysis improves markedly with at least 100 observations (Dancey \& Reidy, 2013).

The average PSM response data for innovative managers was divided into the following categories (Category 1 - low for PSM averages between 1 and 2.9, Category 2 - medium for PSM averages between 3.0 and 3.9 and Category 3 - high for PSM averages between 4.0 and 5.0 ), which were considered significant with a $p$ value $<0.10$. This technique made it possible to identify which government managers were grouped together by statistically relevant similarities. These measurements were determined in accordance with the researcher's judgment and in line with Fisher (Fisher, 1950) "if $P$ is between 0.1 and 0.9 there is certainly no reason to suspect the hypothesis tested [...] We shall not often be astray if we draw a conventional line at $0.05[\ldots]$; however, the viability and reliability of the measurement was taken into account (Hair et al., 2005).

\section{Results}

\section{Descriptive analysis}

The overall PSM average and the standard deviation found in Buiatti and Shinyashiki's study (2007) of public servants in general were 3.37 and 0.698 , respectively. To make the results more intuitive, the Likert scale was inverted from 1- Totally agree to 5-Totally disagree, to 1-Totally disagree to 5-Totally agree. This inversion for comparison purposes was accomplished for the study above as well as our data for innovative government managers, and this is compatible with data transformation rules (Hair et al., 2005). After transforming the data, the average and standard deviations for public servants in general were 2.63 and 0.698 , respectively, and the average and standard deviation for innovative government managers were 3.54 and 0.681 .

Questionnaires were sent by email to our target sample using Google forms on June 20, 2016, and responses were accepted until July 18, 2016. Along with the mailing, telephone calls were made to encourage the public servants to respond to the questionnaire. This included the PSM questionnaire and eight other questions with social-demographic data for this group of 124 innovative public servants. We obtained 102 responses, which represent a response rate of approximately $82 \%$.

In the demographic data for the 102 questionnaires, there were two cases of age being omitted and three cases of empty level of education responses. The number of pieces of missing data was low considering that out of the 24 PSM questions, in the 102 received questionnaires, only five of them featured one missing question response apiece. The 
REGE 27,3

Kolmogorov-Smirnov (KS) test was applied to verify the normality of the data, and the results indicated a normal distribution.

Taking into account the age of the managers, most of the innovative public servants are younger than 40 years old. In all, $80 \%$ of these public servants are younger than 45 years old. Total of $90 \%$ of these government managers have been in their positions for less than 15 years. Considering the estimate of 35 years of an active working life, these public servants are less than half of the way on the road to retirement. Table 1 deals with the distribution of innovative government managers by position.

Of interest in Table 1 is the fact that $51 \%$ of the innovative public servants are IT specialists, and they make up $22 \%$ of the total of the nine types of government managers in Goiás. This accentuated participation of IT specialists in innovative projects has been confirmed by the study by Djellal et al. (2013) in which the authors affirmed that the focus of innovation over the last 30 years has been centered on the search for new technologies, which suggests a very strong culture of innovation in professionals directly involved with technology.

Aggregating the information in Table 1, we found that out of a total of 102 respondents, $31.4 \%$ are female and $68.6 \%$ are male. This does not indicate a predominance of males among innovative public servants, given that only $18 \%$ of all IT managers are female. These data could indicate that the IT area is male-dominated in Brazil.

In terms of marital status, $11.8 \%$ are single, $77.5 \%$ married, $7.8 \%$ separated or divorced and $2.9 \%$ fall within other types of marital status such as stable unions. In terms of education, $14.7 \%$ have college degrees, $64.7 \%$ are specialists, $18.6 \%$ have masters' degrees and $2 \%$ have doctorates degrees.

The college degree in terms of innovative government managers was distributed in the following manner: $53.5 \%$ studied information systems, $10.1 \%$ engineering, $11.1 \%$ administration, $8.1 \%$ economics, $4 \%$ law and $13.1 \%$ studied other areas. In terms of appointed positions, $64.7 \%$ do not have head positions, $23.5 \%$ are in head positions, $2.9 \%$ are superintendents and $8.8 \%$ have other types of appointed positions.

\section{Comparison of the overall public servers PSM index with the index for innovative government managers}

As displayed in Table 2, the $t$-test was significant at an $\alpha$ of $5 \%$; therefore, the average PSM of innovative government managers is considered statistically greater than the overall average PSM for public servants studied in the comparison study of Buiatti \& Shinyashiki (2007).

The discovery that innovative government managers have a significantly higher PSM $(p<0.05)$ than public servants overall may be relevant from the point of view of the public

Table 1. Distribution of Innovative government managers by position

\begin{tabular}{lcccc}
\hline & Frequency & Percentage & Valid percentage & Cumulative percentage \\
\hline Treasury & 4 & 3.9 & 3.9 & 3.9 \\
Finance and control & 13 & 12.7 & 12.7 & 16.7 \\
Oversight and regulation & 2 & 2.0 & 2.0 & 18.6 \\
Legal & 2 & 2.0 & 2.0 & 20.6 \\
Budget and planning & 15 & 14.7 & 14.7 & 35.3 \\
Government & 10 & 9.8 & 9.8 & 49.1 \\
Natural resources & 4 & 3.9 & 3.9 & 100.0 \\
Information technology & 52 & 51.0 & 51.0 & \\
Total & 102 & 100.0 & 100.0 & \\
Source(s): Study data & & & &
\end{tabular}




\begin{tabular}{lccr}
\hline & Innovative & Overall & $\begin{array}{r}\text { Does PSM } \\
\text { matter? }\end{array}$ \\
\cline { 1 - 3 } Average & 3.541078431 & 2.63 & \\
Variance & 0.464989915 & 0.492592593 & \\
Observations & 102 & 190 & \\
Average difference hypothesis & 0 & & $\mathbf{2 7 1}$ \\
Gl & 10.77364703 & & \\
Stat $t$ & $3.61546 E-22$ & & \\
$P(T<=t)$ uni-caudal & 1.65207292 & & Table 2. \\
$t$ critical uni-caudal & $7.23093 E-22$ & & PSM average $t$-test \\
$P(T<=t)$ bi-caudal & 1.971217013 & & \\
$t$ critical bi-caudal & & & \\
Source(s): Study data & & & \\
\hline
\end{tabular}

sector administration, because it confirms a statistical tendency that could indicate to government administrators that it would be advantageous for them to invest in actions that increase public servant PSM since these servants with high PSM are more innovative. However, it should be emphasized that we are not determining causality, which is not the objective in question.

\section{Social-demographic characterization of PSM profile}

MCA and HCA were performed for a sample of 102 observations. All the social-demographic and categorized average data of the PSM questionnaire were evaluated. The performed analysis verified a $59.97 \%$ cumulative percentage in the two first factorial axes, in accordance with Figure 1. This analysis found a 90\% significance level in the correlation of the PSM, the key variable in this analysis, with the other variables. Considering the relevant information in relation to the factorial axes (Figure 1), in the first factorial axis (the $x$ axis), in relation to the origin, Clusters 2 and 3 were separated from the public servants in Cluster 1 . In the second factorial axis (the $y$ axis), in relation to the origin, the public servants with low Category 1 PSM (Cluster 3) were separated from the public servants with medium Category 2 PSM and high Category 3 PSM (Clusters 1 and 2).

The HCA verified the best separation of the three groups, according to the dendrogram presented in Figure 2. Cluster I grouped the following variables: position in IT $(\phi<0.0001)$, educational background in IT $(\phi<0.0001)$, length of public service of $5,6,8,9,10,13$ years $(p<0.1)$, masculine gender $(p=0.022)$, age between 30 and $49(p=0.048)$, PSM Category 2 with an average between 3.0 and $3.9(\phi=0.052)$, college graduate level of education $(p=0.072)$, educational background in law $(\phi=0.080)$, married marital status $(\phi=0.082)$ and professionals without a commissioned position $(\phi=0.089)$.

Cluster II grouped the following variables: length of public service of 8 to 12 years $(p<0.1)$, position in the treasury $(\phi<0.0001)$, appointed position of superintendent $(\phi=0.009)$, age above $50(p=0.015)$, PSM Category 3 with an average between 4.0 and $5.0(p=0.075)$, feminine gender $(\phi=0.077)$, graduate school and master's degree level of education $(p=0.081)$, position in budget and planning $(p=0.081)$, separated or divorced marital status $(p=0.087)$ and an educational background in engineering $(p=0.08)$.

Cluster III grouped the following variables: length of service of 14 to 15 years $(\phi<0.1)$, educational background in economics $(\phi<0.0001)$, positions in budget and planning and government $(\phi<0.0001)$, educational background in administration $(\phi<0.0001)$, positions in natural resources and finance and control $(p<0.0001)$, PSM Category 1 with an average between 1.0 and $2.9(p=0.069)$, female $(\phi=0.058)$, single marital status $(\phi=0.086)$, age above $50(p=0.088)$, educational background in engineering $(p=0.98)$, commissioned position in 


\section{REGE}

27,3

Figure 1.

Graph of MCA of social-demographic data with categorized average PSM data based on the evaluated responses from 102 government managers

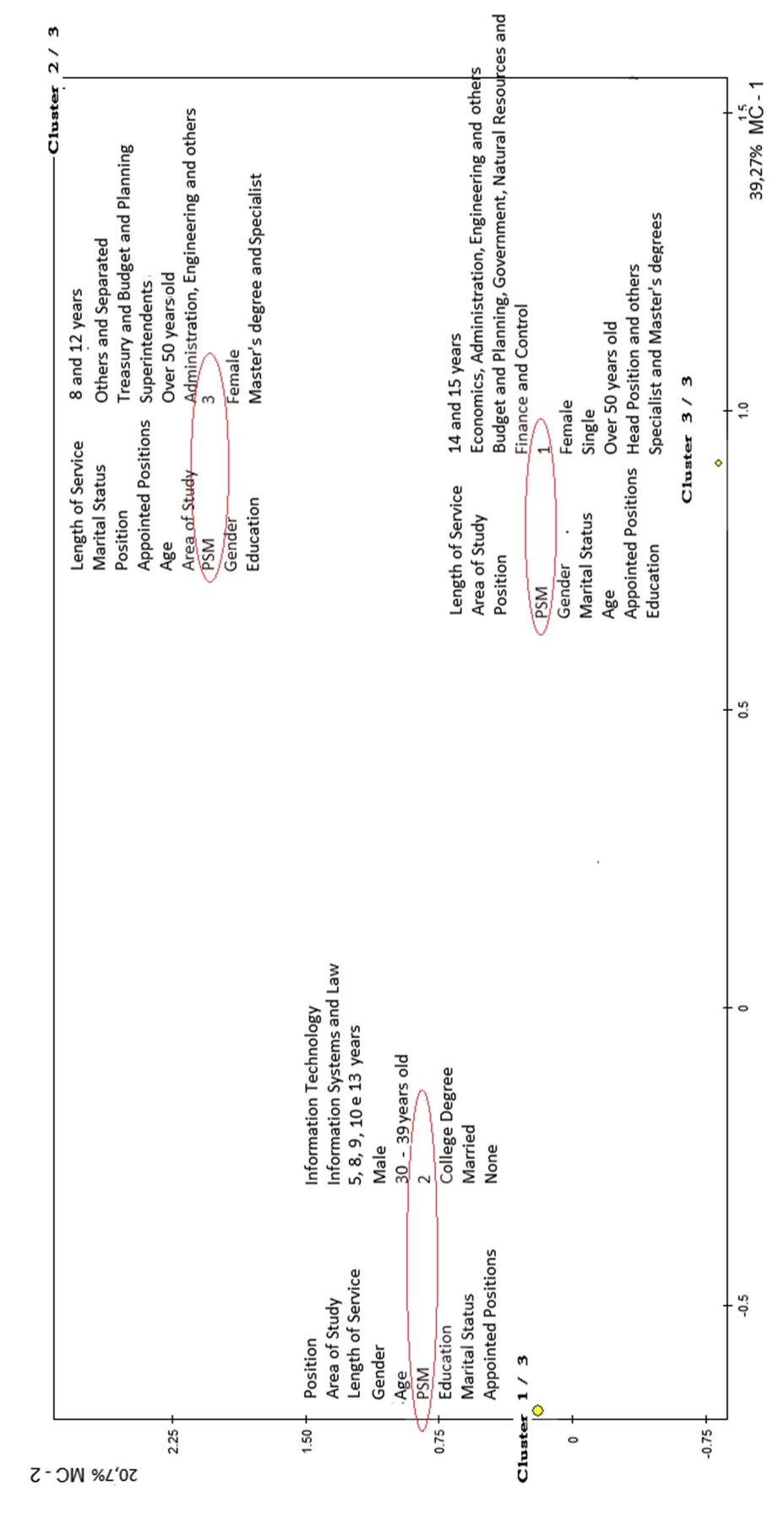




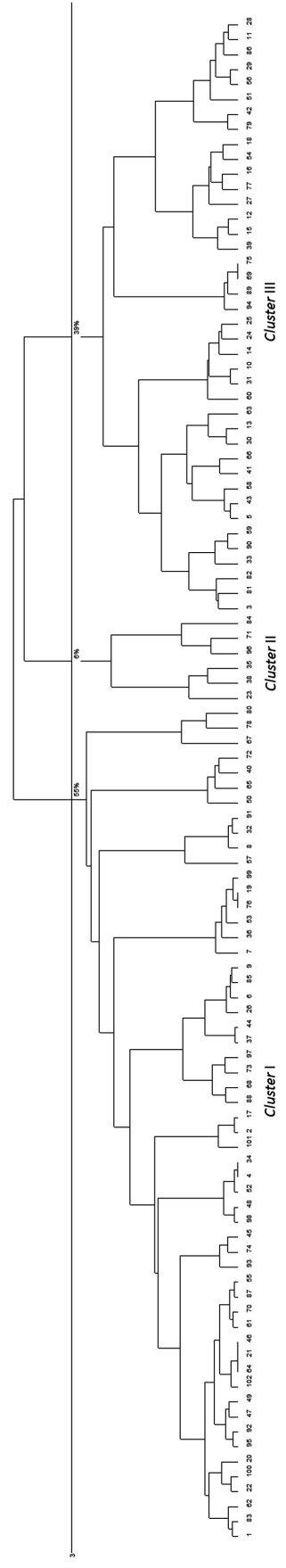

Does PSM

matter?

273

Figure 2.

Dendrogram representing $\mathrm{HCA}$ divided into three clusters of socialdemographic and categorized average PSM data 
REGE 27,3 management $(p=0.098)$, graduate school level of education $(\phi=0.098)$ and a master's degree level of education $(\phi=0.001)$.

\section{Discussion}

In general, the study's results are consistent with the literature, demonstrating that PSM has a positive correlation with level of education, age, the female gender, though with a decreasing tendency, upper levels of the hierarchy (Bright, 2005; Giauque, Ritz, Varone, \& Anderfuhren-Biget, 2012; Perry, 1997; Perry, Brudney, Coursey, \& Littlepage, 2008) and the predominance of the IT area and IT professionals (Djellal et al., 2013).

Analyzing just the cluster in which the categorized PSM was high (Category 3), we can observe, in our sample, a predominance of the female, graduate degrees and ages above 50 which conform with Perry's findings (1997) in which these variables affect PSM, and it was concluded that public servants with higher PSM tend to be older and have higher levels of education. The findings that women are likely to be more intrinsically motivated than men and the existence of a positive correlation between educational level and greater PSM, are consistent with Houston (2011).

The fact that public servants over 50 years of age are present in the high (Category 3) PSM cluster as well as the low (Category 1) PSM cluster is not incongruous. Just as Perry's study (1997) shows that age has a positive relationship with the level of PSM, Giauque et al. (2012) found that seniority has a positive correlation with resignation, which, in the sense of that study, had a negative connotation of being complacent.

Innovative public servants who are in the appointed position of superintendent and other appointed positions have been grouped in the cluster with high (Category 3) PSM which is consistent with the findings of Bright (2005). This author identified the profile of public servants with high PSM through an empirical study in which it was perceived that high PSM has a significant positive correlation with the feminine gender, a high level of education and management positions. Government managers in appointed head positions have been grouped in the cluster with low PSM can be explained by the fact that when the questionnaire was given, the government of the state suspended the process of meritocracy for appointed head positions which may have caused these low results. According to Monteiro (2013), the culture of favoritism predominant in Brazil makes it difficult to professionalize public administration.

On the other hand, Giauque et al. (2012) found that men in the lower level of the hierarchy with low levels of education who have been working in the same organization for a long time have high levels of resignation. This may partially explain the fact that a significant number of public servants with 14 and 15 years of public service are grouped in the cluster with low PSM (Category 1), given that the career of government public servants in Goiás lasts 15 years.

Perry et al. (2008), in a study of award winning volunteer public servants, discovered a strong correlation between PSM and the feminine gender and religious activity, but this correlation has diminished over the past two decades. The authors attributed a weakening in intrinsic values of women to the changing gender roles of men and women. This factor may explain why the feminine gender appears in the low PSM cluster as well as the high PSM cluster.

It is important to note that of the 61 projects registered in the first SINDGESTOR project competition, just 12 had a single author. It may indicate that the culture of innovation is more of a group process than an individual one, and this idea is consistent with the findings of Schein (1990) who argues that cultural force is also a function of group stability.

Public servants with a background in economics are mainly grouped in the low PSM cluster. This could be explained by the influence of economic theories that focus on Homo 
economicus, such as public choice theory and agency theory. These theories are characterized by utilitarianism and a pessimistic view of human personality (Davis et al., 1997; Prebble, 2014).

Djellal et al. (2013) stress the importance of seeding a culture of innovation. IT public servants, for example, made up most of the innovative public servants, which is in accordance with another study by the author which finds that almost three decades of innovation have been based primarily on the work of professionals with backgrounds in IT.

The authors believe that the article has special relevance to the current political and economic moment, marked by urgent and complex social demands that require public services based on effectiveness. In this context, the study of the relationship between PSM and public sector innovation may contribute to the current discussion about the administrative reform of the Brazilian state.

\section{Limitations}

Among the limitations of this study, we can highlight the limited sample. This study was conducted just for a strategic-level career track (government managers); given that, there are other strategic career tracks such as prosecutors and auditors. The career of government managers in Goiás state in Brazil has only 15 years, which limited the spectrum of length of service in position analysis. On the other hand, this may be an opportunity for future research.

Another limitation is the fact that the sample has a high number of young managers. Therefore, the results should be interpreted with due caution about a possible age bias.

\section{Conclusion}

This article contributes to academia as it fills a gap in studies that associate the level of PSM with the innovation practices in the public sector, as well as verify the profile of public servants with high levels of motivation in public service (PSM). For the practice, the discovery that innovative government managers have a significantly higher $\operatorname{PSM}(\phi<0.05)$ than public servants overall may be relevant, because it confirms a statistical tendency that it would be advantageous for public policy-makers to invest in actions that increase public servant PSM since these servants with high PSM are more innovative.

Returning to this study's initial question - is there a difference between the overall PSM level of public servants and innovative public servants? The answer is yes with our finding of a statistical likelihood, not causality. In terms of the second question - what is the PSM profile of these innovative public servants? Some conclusions were obtained. This study's results are consistent with the literature, demonstrating that PSM has a positive correlation with educational level, greater age, the feminine gender (but this tendency has been decreasing) and upper levels of the hierarchy (Bright, 2005; Giauque et al., 2012; Perry, 1997; Perry et al., 2008). The fact that a significant portion of the innovative public servants with high PSM has commissioned positions is consistent with Bright (2005). We have also found that it is important to spread a culture of innovation (Djellal et al., 2013).

We were not able to find a previous study which associated PSM with the practice of innovation among public servants. These results can serve as a point of departure or a stimulus for future works, such as comparing the relationship between PSM and innovation under different public policies in the same country or region, or between countries with different levels of development. Given the scarcity of financial resources that the public administration environment is facing, innovation is becoming more and more imperative. 
REGE 27,3

\section{References}

Arundel, A., \& Huber, D. (2013). From too little to too much innovation? Issues in measuring innovation in the public sector. Structural Change and Economic Dynamics, 27, 146-159. doi: 10.1016/j.strueco.2013.06.009.

Ballart, X., \& Riba, C. (2015). Contextualized measures of public service motivation: the case of Spain. International Review of Administrative Sciences, 83(1), 43-62. doi: 10.1177/0020852315574995.

Bandura, A. (1969). Social-learning theory of indenficatory process. In Company, R.M. (Eds.). Handbook of socialization theory and research, Chicago: Rand McNally \& Company.

Bandura, A. (1977). Self-efficacy: Toward a unifying theory of behavioral change. Psychological Review, 84(2), 191-215. doi: 10.1037/0033-295X.84.2.191.

Bellé, N. (2013). Experimental evidence on the relationship between public service motivation and job performance. Public Administration Review, 73(1), 143-153. doi: 10.1111/j.1540-6210.2012. 02621.x.

Bloch, C., \& Bugge, M.M. (2013). Public sector innovation-from theory to measurement. Structural Change and Economic Dynamics, 27(0), 133-145. doi: 10.1016/j.strueco.2013.06.008.

Bobbio, N. (2000). Estado, poder e governo Estado, governo e sociedade: para uma teoria geral da politica. 8a ed.. Rio de Janeiro: Paz e Terra, Vol. 69, pp. 53-133.

Borins, S. (2000). Loose cannons and rule breakers, or enterprising leaders? Some evidence about innovative public managers. Public Administration Review, 60(6), 498-507.

Borins, S. (2001). Encouraging innovation in the public sector. Journal of Intellectual Capital, 2(3), 310-319. doi: 10.1108/14691930110400128.

Bozeman, B., \& Su, X. (2014). Public service motivation concepts and theory: A critique, Public Administration Review, n/a-n/a. doi: 10.1111/puar.12248.

Brandão, S.M., \& Bruno-Faria, M.d. F. (2013). Inovação no setor público: Análise da produção científica em periódicos nacionais e internacionais da área de administração. Revista de Administração Pública, 47, 227-248.

Brehm, J., \& Gates, S. (1999). Working, shirking, and sabotage: Bureaucratic response to a democratic public, Ann Arbor: University of Michigan Press.

Bresser-Pereira, L.C. (2009). Os primeiros passos da reforma gerencial do Estado de 1995. Revista Eletrônica sobre a Reforma do Estado, 16, 1-36.

Bright, L. (2005). Public employees with high levels of public service motivation: Who are they, where are they, and what do they want?. Review of Public Personnel Administration, 25(2), 138-154. doi: 10.1177/0734371x04272360.

Buiatti, C.L., \& Shinyashiki, G.T. (2007). Validação da escala de PSM - public service motivation por meio de modelagem de equações estruturais. Ribeirão Preto: Mestrado Dissertação), Universidade de São Paulo.

Buiatti, C.L., \& Shinyashiki, G.T. (2011). Gestão de RH no Setor Público: Validação da Escala de PSM - public Service Motivation, IJIE - Iberoamerican Journal of Industrial Engineer, 3(1), 22.

Cavalcante, P., Magalhães, A., \& Goellner, I. (2019). Laboratórios e Equipes de Inovaçãa na Administração Pública Brasileira: indutores e barreiras dessa nova tendência, Salvador: SBAP.

Cohen, J., Cohen, P., West, S.G., \& Aiken, L.S. (2013). Applied multiple regression/correlation analysis for the behavioral sciences, Abingdon: Routledge.

Costin, C. (2010). Administração pública. Rio de Janeiro: Elsevier.

Crewson, P.E. (1997). Public-service motivation: Building empirical evidence of incidence and effect. Journal of Public Administration Research and Theory, 7(4), 499-518.

Dancey, C.P., \& Reidy, J. (2013). Estatística sem matemática para psicologia. 5th ed., Porto Alegre: Penso Editora. 
Davis, R.S. (2010). The ABCs of public service motivation: Altruism, behavior, and compensation. Journal of Public Administration Research and Theory, 20(4), 887-897. doi: 10.1093/jopart/muq041.

Davis, J.H., Schoorman, F.D., \& Donaldson, L. (1997). Toward a stewardship theory of management. Academy of Management review, 22(1), 20-47.

Djellal, F., Gallouj, F., \& Miles, I. (2013). Two decades of research on innovation in services: Which place for public services?. Structural Change and Economic Dynamics, 27(0), 98-117. doi: 10.1016/j.strueco.2013.06.005.

Ferreira, V.d. R.S., Najberg, E., Ferreira, C.B., Barbosa, N.B., \& Borges, C. (2014). Inovação em serviços de saúde no Brasil: Análise dos casos premiados no concurso de Inovação na administração pública federal. Revista de Administração Pública, 48(5), 1207-1228.

Fisher, R.A. (1950). Statistical methods for research workers. Biological monographs and manuals. 11th ed., No. V, Statistical methods for research workers. Biological monographs and manuals. No. V.

Gallouj, F., \& Zanfei, A. (2013). Innovation in public services: Filling a gap in the literature. Structural Change and Economic Dynamics, 27(0), 89-97. doi: 10.1016/j.strueco.2013.09.002.

Giauque, D., Ritz, A., Varone, F., \& Anderfuhren-Biget, S. (2012). Resigned but satisfied: the negative impact of public service motivation and red tape on work satisfaction. Public Administration, 90(1), 175-193. doi: 10.1111/j.1467-9299.2011.01953.x.

Goiás, S.E.D. (2018). Saúde ganha prêmio em inovação pública. Available from: http://www.saude.go. gov.br/saude-ganha-premio-em-inovacao-publica/.

Hair, J.F., Anderson, R.E., Tatham, R.L., \& Black, W.C. (2005). Análise Multivariada de Dados. Sant'Anna, A.S., \& Neto, A.C., Trans. 5th ed., Porto Alegre: Bookman.

Harman, H.H. (1976). Modern factor analysis, Chicago: University of Chicago Press.

Hartley, J. (2005). Innovation in governance and public services: Past and present. Public money and management, 25(1), 27-34.

Herzberg, F. (1987). One more time: How do you motivate employees?. Harvard Business Review, (87507), 16.

Horton, S. (2008). History and persistence of an idea and an ideal. In Hondeghem, J.L.P.A. (Eds.), Motivation in Public Management. The Call of Public Service First ed., New York, NY: Oxford University Press. 17-32.

Houston, D.J. (2011). Implications of occupational locus and focus for public service motivation: Attitudes toward work motives across nations, Public Administration Review, 71(5), 761-771. doi: 10.1111/j.1540-6210.2011.02415.x.

Jacob, S., Schiffino, N., \& Biard, B. (2016). The mystery shopper: A tool to measure public service delivery?. International Review of Administrative Sciences, 84(1), 164-184. doi: 10.1177/ 0020852315618018.

Jacobi, P., \& Pinho, J.A. (2006). Inovação no campo da gestão pública local: novos desafios, novos patamares. In E. FGV (Ed.), (pp. 23-39), Rio de Janeiro: FGV Editora.

Jacobson, W.S. (2011). Fall creating a motivated workforce: How organizations can enhance and develop public service motivation (PSM). Public Personnel Management, 40, 215.

Kernaghan, K. (2011). Getting engaged: Public-service merit and motivation revisited. Canadian Public Administration, 54(1), 1-21. doi: 10.1111/j.1754-7121.2011.00158.x.

Koehler, M., \& Rainey, H.G. (2008). Interdisciplinary foundations of public service motivation. In Hondeghem, J.L.P.A. (Eds.), Motivation in Public Management. The Call of Public Service. 1st ed., New York, NY: Oxford University Press. pp. 33-55.

Latham, G.P. (2007). Work motivation: History, theory, research, and practice. 2 ed., Los Angeles: SAGE.

Leisink, P., \& Steijn, B. (2009). Public service motivation and job performance of public sector employees in the Netherlands, International Review of Administrative Sciences, 75(1), 35-52. doi: 10.1177/0020852308099505. 
REGE 27,3

Liu, B. (2009). Evidence of public service motivation of social workers in China. International Review of Administrative Sciences, 75(2), 349-366. doi: 10.1177/0020852309104180.

Liu, B., \& Perry, J.L. (2016). The psychological mechanisms of public service motivation:A two-wave examination, Review of Public Personnel Administration, 36(1), 4-30. doi: 10.1177/0734371x14549672.

Liu, B., Perry, J.L., Tan, X., \& Zhou, X. (2018). A cross-level holistic model of public service motivation. International Public Management Journal, 21(5), 703-728.

Mann, G.A. (2006). A motive to serve: Public service motivation in human resource management and the role of PSM in the nonprofit sector. Public Personnel Management, 35, 33.

Maslow, A.H. (1943). A theory of human motivation, Psychological Review. 50(4), 370-396. doi: 10.1037/ h0054346.

Monteiro, L.M. (2013). Reforma da administração pública e carreiras de Estado: o caso dos especialistas em políticas públicas e gestão governamental no poder executivo federal. Revista de Administração Pública, 47, 1117-1143.

Mori, Y., Kuroda, M., \& Makino, N. (2016). Nonlinear Principal Component Analysis and Its Applications, New York: Springer.

Pandey, S.K., \& Stazyk, E.C. (2008). Antecedents and correlates of public service motivation. In J.L.P.A. Hondeghem (Eds.), Motivation in Public Management. The Call of Public Service. First ed., New York, NY: Oxford University Press. 101-117.

Paulla, C.R.D.H., \& Kavita, M. (2015). Gestão da qualidade e inovação: evidências para empresas do segmento de alimentação no oeste goiano. Revista Gestão e Desenvolvimento, 12(2), ISSN: $2446-6875$.

Perry, J.L. (1996). Measuring public service motivation: An assessment of construct reliability and validity. Journal of Public Administration Research and Theory, 6(1), 5-22.

Perry, J.L. (1997). Antecedents of public service motivation. Journal of Public Administration Research and Theory, 7, 17.

Perry, J.L. (2010). Introduction to the symposium on public service motivation research. Public Administration Review, 70(5), 679-680. doi: 10.1111/j.1540-6210.2010.02195.x.

Perry, J.L., \& Hondeghem, A. (2008). Motivation in public management: The call of public service. New York, NY: Oxford University Press.

Perry, J.L., Brudney, J.L., Coursey, D., \& Littlepage, L. (2008). What drives morally committed citizens? A study of the antecedents of public service motivation. Public Administration Review, 68(3), 445-458. doi: 10.1111/j.1540-6210.2008.00881.x.

Prebble, M. (2014). Has the study of public service motivation addressed the issues that motivated the study?. The American Review of Public Administration. doi: 10.1177/0275074014554651.

Schein, E.H. (1990). Organizational culture. American Psychologist, 45(2), 109-119. doi: 10.1037/0003066X.45.2.109.

Schott, C., van Kleef, D.D., \& Steen, T. (2015). What does it mean and imply to be public service motivated?. The American Review of Public Administration, 45(6), 689-707.

Schumpeter, J.A. (2008). Capitalism, socialism, and Democracy. New York: Harper Perennial Modern Thought.

Sousa, M.d. M., Ferreira, V.D.R.S., Najberg, E., \& Medeiros, J.J. (2015a). Portraying innovation in the public service of Brazil: Frameworks, systematization and characterization, Revista de Administração (São Paulo), 50(4), 460-476.

Sousa, M.d. M., Ferreira, V.d. R.S., Najberg, E. and Medeiros, J.J. (2015b). Portraying innovation in the public service of Brazil: Frameworks, systematization and characterization. Revista de Administração (São Paulo), 50, 460-476.

Stazyk, E.C. (2013). Crowding out public service motivation? Comparing theoretical expectations with empirical findings on the influence of performance-related pay. Review of Public Personnel Administration, 33(3), 252-274. doi: 10.1177/0734371x12453053. 
Struecker, D.R., \& Hoffmann, M.G. (2017). Participação social nos serviços públicos: Caracterização do estado da arte por meio da bibliometria e da revisão sistemática. REGE-Revista de Gestão, 24(4), 371-380.

Taylor, J., \& Taylor, R. (2011). Working hard for more money or working hard to make a difference? Efficiency wages, public service motivation, and effort. Review of Public Personnel Administration, 31(1), 67-86. doi: 10.1177/0734371x10394401.

Tidd, J., Bessant, J., \& Pavitt, K. (2008). Gestão da inovação. Tradução de Elizamari Rodrigues Becker. Porto Alegre: Bookman. [et al.].

Van Loon, N.M., Vandenabeele, W., \& Leisink, P. (2015). On the bright and dark side of public service motivation: The relationship between PSM and employee wellbeing. Public Money \& Management, 35(5), 349-356.

Vandenabeele, W. (2009). The mediating effect of job satisfaction and organizational commitment on self-reported performance: More robust evidence of the PSM-performance relationship. International Review of Administrative Sciences, 75(1), 11-34. doi: 10.1177/0020852308099504.

Vandenabeele, W., \& Walle, S.V.d. (2008). International differences in public service motivation: Comparing regions across the world. In Hondeghem, J.L.P.A. (Eds.), Motivation in Public Management. The Call of Public Service (First ed. ed., pp. 223-244). New York: Oxford University Press Inc.

Williams, H. (2012). Innovation inducement prizes: Connecting research to policy. Journal of Policy Analysis and Management, 31(3), 752-776.

\section{About the authors}

Ellysson Fernandes Rosa has worked for more than 18 years as government manager. He is Professor of Public Administration at FacUnicamps and his research is focused in the areas of ethics, motivation and quality of life, applied to the public administration and citizenship. Ellysson Fernandes Rosa is the corresponding author and can be contacted at: ellyssonrosa@gmail.com

Estela Najberg has been an associate professor at the Federal University of Goiás for 11 years, working in the undergraduate and postgraduate courses. Research and teaching in the areas of public administration, public policy, social/environmental corporate responsibility and creative economy.

Marcos de Moraes Sousa is public administrator professor at Goiano Federal Institute and Goias Federal University. His research is focused in public service innovation and judicial administration.

Associate Editor: Luis Pinochet

For instructions on how to order reprints of this article, please visit our website:

www.emeraldgrouppublishing.com/licensing/reprints.htm

Or contact us for further details: permissions@emeraldinsight.com 